\title{
The Use of Intraoperative Radiation Therapy (IORT) in Multimodality Management of Cancer Patients. A Single Institution Experience.
}

\author{
Ahmed Elashwah ( $\square$ ashwah_a80@yahoo.com ) \\ Cairo University KasrAlainy Center of Radiation Oncology and Nuclear Medicine https://orcid.org/0000-0003-1962-8271 \\ Abdullah Alsuhaibani \\ King Saud University \\ Ayman Azzam \\ KFSH\&RC: King Faisal Specialist Hospital and Research Center \\ Belal Moftah \\ KFSH\&RC: King Faisal Specialist Hospital and Research Center \\ Muhammed Hussein \\ KFSH\&RC: King Faisal Specialist Hospital and Research Center \\ Shada ALramahi \\ KFSH\&RC: King Faisal Specialist Hospital and Research Center \\ Tarek Amin \\ KFSH\&RC: King Faisal Specialist Hospital and Research Center \\ Rana Mahmoud \\ KFSH\&RC EHP: King Faisal Specialist Hospital and Research Centre Environmental Health Program \\ Mohammed BREAKEIT \\ KFSH\&RC: King Faisal Specialist Hospital and Research Center \\ Zeinab Hassan \\ KFSH\&RC: King Faisal Specialist Hospital and Research Center \\ Ali Alzahrani \\ KFSH\&RC: King Faisal Specialist Hospital and Research Center
}

\section{Research Article}

Keywords: IORT, multimodality, management, cancer

Posted Date: November 19th, 2021

DOI: https://doi.org/10.21203/rs.3.rs-1086719/v1

License: (c) (i) This work is licensed under a Creative Commons Attribution 4.0 International License. Read Full License

Version of Record: A version of this preprint was published at Journal of Gastrointestinal Cancer on March 15th, 2022. See the published version at https://doi.org/10.1007/s12029-021-00786-9. 


\section{Abstract}

\section{Background}

Intraoperative radiation therapy (IORT) is a highly conformal technique given in the operating room in many cancer sites for better tumor local control by increasing the tumor radiation dose without exceeding normal tissues tolerance doses.

\section{Purpose}

Assess the feasibility of Intra operative radiation therapy (IORT) and short-term toxicity in patients with different cancer sites treated with a multidisciplinary protocols including IORT.

\section{Patients \& Methods}

Medical records of cancer patients who received IORT at King Faisal Specialized Hospital and Research center(KFSHRC), Riyadh, Saudi Arabia from 2013 until 2017 were retrospectively reviewed.

\section{Results}

Total 188 patients with 212 IORT applications were analyzed. Twenty-four patients had more than one application.116 patients were males. Median age at time of diagnosis was 49.5years (19-77). Hundred thirty four patients had primary while 54 cases had recurrent disease. Gastro esophageal cancer and soft tissue sarcoma were the most frequent diagnosis in 49 patients followed by colorectal cancer in 35 patients. Major surgeries with curative intent done in 183 patients (97.3\%) and 118 patients (62.8\%) had hyperthermic intraperitoneal chemotherapy (HIPEC) in addition to IORT. The 30 days postoperative mortality rate was $3.2 \%$. Fifty-three (28.2\%) patients develop Grade III-IV complications according to Clavien-Dindo grading system.

\section{Conclusion}

The data presented discussing treatment modalities for different malignant tumors which are treated and may benefit from using IORT technique as a part of multimodality treatment. IORT seems safe and feasible, however a longer follow-up is needed for proper evaluation and defining the role of IORT in tailored multimodality approach.

\section{Introduction}

Intraoperative irradiation (IORT) is a highly conformal radiation therapy modality entailing the delivery of radiation at the time of surgery to increase the tumor radiation dose, aiming to improve tumor local control rate with respect to surrounding normal tissue tolerance doses (1).

The IORT as a technique is not a new modality, but it was first used about 100 years ago (2). The rationale behind using IORT in addition to external beam radiation therapy(EBRT) in many cancer sites is to improve the therapeutic ratio by (1) decreasing the radiation "boost" volume field by direct tumor/tumor bed visualization in contrast to the traditional large EBRT fields which encompass the primary tumor and surrounding normal structures for potential microscopic disease thus allow for more conformal treatment (2) decrease the dose to surrounding risk structures by removal of part or all of it by mobilization, shielding or changing electron beam energy $(3,4)$.

In our study, we retrospectively evaluate the feasibility and short-term complications for patients treated with IORT in our Center King Faisal Specialized Hospital and Research center (KFSHRC)as a part of multimodality management for different tumor sites.

\section{Materials And Methods}

The medical records of patients who received IORT as part of their multidisciplinary treatment in our institution KFSH\&RC from 2013 until 2017 were retrospectively evaluated with particular focus on the clinical and technical aspects of IORT treatment. Figure 1 represents the number of cases included in the study each year.

The data collected includes (age, sex, cancer site, histopathology, type of surgery done and its aim (curative or palliative), hyperthermic intraperitoneal chemotherapy (HIPEC) were used or not, IORT details (dose, energy, applicator diameter, beam angle, total treatment depth and bolus is used or not) and postoperative complications according to the Clavien-Dindo grading system.

IORT is used in our center in addition to surgery in the management of patients with different cancer sites with the following inclusion criteria: 1) Age below 75 years, (2) Eastern Cooperative Oncology Group (ECOG) performance status $\leq 2$, (3) Satisfactory laboratory work, 4) proven diagnosis of malignancy confirmed by preoperative biopsy, (5) no evidence of distant extra abdominopelvic metastasis to liver, lungs, brain, or 
bones, and (6) signed written informed consent by patients. HIPEC is added only if there is evidence either radiologically or pathologically, of peritoneal involvement.

Major surgeries with curative intent were done for the majority of patients, immediately at the end surgical resection IORT is used using Mobetron, the IORT dose delivered usually dependent on margin status (R), location of nearby risk structures and dose of previous radiation therapy if any. A dose of 10-15 Gy was used for those patients with R0 resection, while a dose of 15-20 Gy was used for those with R1 resection.

The IORT dose is generally calculated from the isodose resulting in proper tumor coverage. Electron energies available range from 6-12 MeV. The electron beam energy chosen depends on the target depth. A bolus is used in many cases to increase the surface dose and decrease the dose to underlying structures, Applicator diameter choice usually depends on the size of the treatment area taking in consideration the preoperative tumor volume (5-7).

In cases with confirmed involvement of the peritoneal surface, HIPEC technique was performed after finishing the IORT procedure, the operative and HIPEC technique details were published earlier in our previous study (8). Many therapeutic agents for HIPEC were used as combination of cisplatin $\left(50 \mathrm{mg} / \mathrm{m}^{2}\right)$ plus doxorubicin $\left(15 \mathrm{mg} / \mathrm{m}^{2}\right)$ infused over 90 minutes or single-agent melphalan $\left(60 \mathrm{mg} / \mathrm{m}^{2}\right)$ infused over $60 \mathrm{minutes}$. The choice of HIPEC therapeutic agent depends on the case as agreed by the treating surgical oncology and medical oncology as a part of a multidisciplinary team.

During HIPEC procedure, all hemodynamic and cardiopulmonary parameters were strictly monitored. At the end of HIPEC procedure, the abdominopelvic cavity was lavaged again about 10-15 times with 1 liter of normal saline.

The 30 days Postoperative complication rates were evaluated according to the Clavien-Dindo grading system (9).

\section{Statistical Analysis}

This study is a retrospective descriptive study focusing on the details of IORT technique. Descriptive statistics were performed for all available categorical variables expressed in either median with range or numbers. The study primary endpoint was 30 days postoperative mortality and morbidity rate.

\section{Results}

Medical records of 188 patients with total 212 IORT applications were reviewed, and 24 patients had more than one application. Male patients were 116. Median age at diagnosis was 49.5years (range 19-77). Detailed cancer type distribution is listed in Table 1 and Figure 2.

Table 1

patients' characteristics

\begin{tabular}{|ll|}
\hline Mean age at diagnosis & $\mathbf{4 9 . 5}$ (19-77) \\
\hline Gender & 116 \\
Fale & 72 \\
Cancer type distribution & \\
Gastro-esophageal & \\
Colorectal & 49 \\
Soft tissue sarcoma & 35 \\
Gynecological malignancy & 49 \\
Genito urinary & 16 \\
Pancreatic cancer & 6 \\
Gall bladder cabcer/ cholangiocarcinoma & 9 \\
Others & 15 \\
\hline
\end{tabular}

Disease status at the time of IORT were as follow;134 patients had primary while 54 cases had recurrent disease, Table 2. 
Table 2

Clinical and therapeutic correlations of surgery performed and technical IORT characteristics according to cancer site.

\begin{tabular}{|c|c|c|c|c|c|c|c|c|c|}
\hline $\begin{array}{l}\text { Tumor } \\
\text { site }\end{array}$ & $\begin{array}{l}\text { Gastro- } \\
\text { esophageal }\end{array}$ & colorectal & $\begin{array}{l}\text { Soft } \\
\text { tissue } \\
\text { sarcoma }\end{array}$ & $\begin{array}{l}\text { Gynecological } \\
\text { malignancy }\end{array}$ & $\begin{array}{l}\text { Genito } \\
\text { urinary } \\
\text { cancer }\end{array}$ & $\begin{array}{l}\text { Pancreatic } \\
\text { cancer }\end{array}$ & $\begin{array}{l}\text { Gall bladder } \\
\text { cancer/cholangiocarcinoma }\end{array}$ & Others & All \\
\hline primary & 49 & 22 & 28 & 7 & 4 & 9 & 4 & 11 & 134 \\
\hline recurrent & 0 & 13 & 21 & 9 & 2 & 0 & 5 & 4 & 54 \\
\hline curative & 48 & 34 & 48 & 16 & 6 & 9 & 9 & 5 & 183 \\
\hline palliative & 1 & 1 & 1 & 0 & 0 & 0 & 0 & 2 & 5 \\
\hline HIPEC & 40 & 25 & 23 & 15 & 2 & 3 & 8 & 2 & 118 \\
\hline $\begin{array}{l}\text { Single } \\
\text { field }\end{array}$ & 48 & 29 & 40 & 14 & 6 & 8 & 7 & 14 & 166 \\
\hline $\begin{array}{l}\text { Multiple } \\
\text { field }\end{array}$ & 1 & 6 & 9 & 2 & 0 & 1 & 2 & 1 & 22 \\
\hline
\end{tabular}

All clinical and technical aspects of IORT treatment (including energy used, doses, and applicator diameter) are illustrated in Figures 3-5.

Major surgery with curative intent done in 183 patients (97.3\%) and 118 patients (62.8\%) had HIPEC in addition to IORT, Table 2.

The 30 days postoperative mortality rate was $3.2 \%$ and 53 (28.2\%) patients developed Grade III-IV complications according to Clavien-Dindo grading system. Figure 6, Tables 3 and 4 showed the incidence of different complication grades for each cancer site and the management done for each type of complications.

Table 3

postoperative complication grades according to Clavien Dindo(CD) grading system in each cancer site.

\begin{tabular}{|c|c|c|c|c|c|c|c|}
\hline \multirow[t]{2}{*}{ Treatment site } & \multicolumn{7}{|c|}{ Postoperative complications Grade } \\
\hline & Grade I & Grade II & Grade Illa & Grade IIIb & Grade IVa & Grade IVb & Grade V \\
\hline Gastroesophageal & & 32 & 7 & 3 & 3 & & 4 \\
\hline Colorectal & 1 & 19 & 10 & 4 & 1 & & \\
\hline sarcoma & 1 & 30 & 6 & 7 & 1 & 2 & 2 \\
\hline Gynecological malignancy & & 9 & 3 & 4 & & & \\
\hline Pancreatic cancer & & 6 & 1 & 2 & & & \\
\hline
\end{tabular}


Table 4

management done for patients with CD grade III and IV

\begin{tabular}{|ll|}
\hline CD grade(No of patients) & management \\
\hline $\mathrm{IIla}(27)$ & 17 patients developed abdominal collection required US or CT guided drainage. \\
& 8 patients developed pleural effusion required thoracocentesis. \\
& 2 patients required nephrostomy tube insertion due to obstructive uropathy. \\
\hline $\mathrm{IIIb}(20)$ & 7 patients developed bowel leakage requiring exploration. \\
& 3 patients developed intra abdominal bleeding requiring exploration with hematoma evacuation. \\
& 4 patients developed wound infection required debridement and flap. \\
& 3 patients developed lymphatic leakage requiring exploration. \\
& 2 patients developed DVT requiring venous thrombectomy \\
& 1 patient developed DVT/PE requiring IVC filter. \\
& 2 patients were de saturated requiring resuscitation $\mathrm{n}$ ICU. \\
& 2 patients admitted with deterioration of consciousness. \\
& 1 patient admitted with massive PE. \\
\hline $\mathrm{IVb}(5)$ & The patients admitted to ICU with multi organ failure \\
\hline
\end{tabular}

\section{Discussion}

The use of external beam radiation therapy (EBRT) in a fractionated manner provides a therapeutic advantage over the single large IORT dose. That advantage is well explained by the "4Rs" of classical radiobiology (normal tissue repair, tumor re-oxygenation, tumor redistribution, and normal tissue repopulation). The large doses per fraction in case of IORT may result in an increased risk of late effects probably due to small blood vessel injury (4), so careful planning and administration of IORT should be applied for limiting the radiation dose to non-target tissues by its exclusion from the radiation field whether by direct inspection, mobilization or shielding (10).

By reviewing our data, it is appeared that the intent of treatment is almost curative in most of cases. The majority, 102 (54.2\%) patients had GIT cancers (49(26\%) had gastric/esophageal, 35 (18.6\%) had colorectal, 9(4.8\%) had gall bladder/cholangiocarcinoma and $9(4.8 \%)$ had pancreatic cancer). Major surgery with curative intent was performed in nearly all patients (except for two patients; $1 \mathrm{gastric/}$ esophageal and $1 \mathrm{colorectal)}$.

The philosophy of using IORT in rectal cancer is to improve tumor local control, especially in patients with locally advanced disease (those with T4b disease) where pelvic recurrence are high. Multiple studies have addressed the value of using IORT in rectal cancer management (11-15). A recent meta-analysis extensively reviewed IORT studies in rectal cancer with a positive interpretation of the results (16), however, the only randomized trial done failed to show an advantage for IORT use in this trial 142 patients diagnosed with rectal cancer were included and randomly assigned into 2 groups after receiving preoperative EBRT(40Gy) (one group underwent surgery alone, the other one received IORT 18 Gy at the time of surgery). No difference between the 2 groups regarding the 5 years local control rate as it was $91.8 \%$ in IORT group vs $92.8 \%$ in surgery alone group $(p=0.6018)(17)$.

Thirty five colorectal cancer cases were included in this study (22 patients with primary while 13 with recurrent disease). Majority of them (97\%) underwent major surgery with curative treatment intent (7 patients required multiple IORT fields). HIPEC was performed in 21 (57\%) patients (11 primary and 10 recurrences). Four patients performed multiple surgeries with repeated HIPEC. Regarding postoperative complications grades, 19 (54.2\%) patients developed grade II, while 10 (28.5\%) patients developed grade Illa requiring intervention with local anesthesia, 4 (11.4\%)patients developed grade IIIb (3 patients had bowel leakage required exploration and one patient developed wound infection required debridement). No reported grade IV B or V complications. Most of these complications could be attributed to the complexity of the surgical procedures and/or HIPEC. These complex cytoreductive surgeries with HIPEC were performed in a high percentage of cases (57\%) (47\% of them had presented with recurrent disease with repeated surgeries and re HIPEC). This was reported previously in a randomized trial conducted by Vic J. Verwaal et al in which they reported that most of the complications from the complex surgical procedures done and HIPEC were related to bowel leakage (18) .

EBRT has an established role for years in the postoperative management of gastric cancer patients with significant improvement of local control rate, disease-free survival (DFS), and overall survival (OS) in comparison to surgery alone $(19,20)$. Multiple studies support using IORT as a treatment option in gastric cancer resulting in a decrease loco-regional recurrence without an increase in complications incidence, however it does not appear to have an impact on overall survival (21-25). 
Forty nine (26\%) patients having gastro esophageal cancer were included in our study, Majority of them (97.9\%) underwent major surgery with curative treatment intent. Forty patients underwent HIPEC. Regarding postoperative complications, grades $65 \%$ developed grade II complications with reported 4 patients died post-operatively (All these patients were more than 70 years). This might raise the question again about the safety of HIPEC in combination with cytoreductive surgery in these old people, actually this question was addressed in many studies; Spiliotis et al (26) and Arslan et al. (27) who concluded a higher incidence of postoperative mortality (12.9\%) in those elderly people versus (7.2\%) in younger patients.

IORT has been used as a part of multi-modality treatment approach in patients with soft-tissue sarcoma, especially retroperitoneal site, taking advantage of higher radiation dose to the target volume with lower dose to surrounding healthy tissues with encouraging local control rate and survival (28-32). Sarcomas beside gastro-esophageal cancer are the most treated tumors in $49(27 \%)$ patients (57.1\% of them had recurrent disease) ,30/49(61.2\%) patients had retroperitioneal site, The intent of the treatment was almost curative with radical resection in majority (98\%) of patients. HIPEC was performed in 23 patients (47\%) with proved peritoneal sarcomatosis. Regarding IORT technical aspects, 23 patients (47\%) required $10 \mathrm{~cm}$ applicator diameters that could be related to the large tumor extension and large post-resection tumor bed. Moreover, 9 patients required complex irradiation with multiple fields by high energy electrons up to $12 \mathrm{Mev}$ and doses up to $15 \mathrm{~Gy}$ in 20 cases ( $40.8 \%$ ). The 30 days postoperative complications grades were as follow; 30 (66.6\%) patients developed grade II and 18 (36.7\%) patients developed grade III complications or more.

The role of cytoreductive surgery (with removal of all macroscopic visible diseases) in advanced primary epithelial ovarian cancer (EOC) has been established with significant improvement of both DFS and OS (33-35), however its value in relapsed epithelial ovarian cancer remains controversial and is not considered as a standard of care because this approach has not been demonstrated in prospective trials. In a retrospective analysis, surgery at first relapse appears to be associated with a survival benefit only when a complete tumor resection can be obtained (36,37). IORT use in gynecological malignancies has been investigated in many series, especially in recurrent disease with better loco regional control rate compared to surgery alone without significant increase in toxicity apart from neuropathy which was more frequent in IORT dose > 20 Gy (38). The largest series evaluating HIPEC for recurrent EOC included 246 patients (184 with platinum-sensitive recurrent EOC), $92 \%$ of whom underwent optimal cytoreductive surgery. HIPEC treatment resulted in a median overall survival (OS) of 49 months; 52 months for platinum-sensitive patients. There was a $12 \%$ incidence of serious (grade $3 / 4$ ) complications, including leukopenia (3\%), intra-abdominal hemorrhage ( $2 \%)$, and postoperative complications $(5 \%)$, including one postoperative death due to an anastomotic leak resulting in peritonitis and acute renal failure (39).

Gynecological malignancy was reported in 16 patients in our study (10 patients had ovarian cancer and 6 patients had uterine sarcoma). Nine (56.2\%) patients had recurrent disease, All patients had major surgery with curative intent. HIPEC performed in most of the cases (93.7\%), with multiple field IORT in two cases. The majority (56\%) of cases developed grade II complications post-operatively, with 4 (25\%) developed grade IIIb complication requiring intervention under general anesthesia.

Pancreatic cancer is one of the most aggressive malignancies with poor outcome, 5 years OS is less than $5 \%$. The resectability rate is only $20-$ $40 \%$ with a maximum 5 -year survival of $30 \%$ in those patients with R0 resection. The need of IORT use in pancreatic cancer may come from the higher incidence of local recurrence (rate is nearly $50 \%$ in 5 years) despite the use of preoperative or postoperative EBRT. IORT could be an interesting therapeutic option for this disease for the purpose of dose intensification to the tumor /tumor bed for better local tumor control, especially in locally advanced cases. The benefits of using IORT in selected pancreatic cancers were widely reported in some trials with significant improvement of both local control and survival (40-42).

Pancreatic cancer was reported in 9 patients in our study. All patients had major surgery with curative intent. HIPEC was performed in 3(33\%) patients with possible carcinomatosis. Multiple IORT fields applied only in one case. Regarding the technical character of IORT, it was found that most of the patients required a larger applicator diameter $(\geq 7.5 \mathrm{~cm})$, probably due to the large surgical field with high incidence of lymph node metastasis. Two thirds of cases developed grade II complications, with only 2 (22.2\%) developed grade IIIb complications (bowel leakage) requiring intervention under general anesthesia.

The main limitations of our study are: 1. Relatively small sample size given the high number of cancer types (low number of subjects per cancer type or per group). 2. Retrospective design. 3. Inability to generalize the results to different populations. 4 . Potential selection bias due to recruitment of patients from only one center.

\section{Conclusion}

The data presented in our study gives an overview on our practice, patient selection and describes treatment modalities (including surgery, IORT, and HIPEC) for a number of tumor types. A longer follow-up is needed for proper evaluation and defining the contribution of IORT in a tailored multimodality approaches and to evaluate whether the use of this technique will improve the local control or survival of the patients by evaluating any potential late side effects. 


\section{Declarations}

\section{Conflicting Interests}

The authors declare no competing interests regarding the production of this paper. The authors have no personal financial or institutional interests in any of the drugs, materials, or devices described in this paper.

\section{Funding}

No funding received from any site to complete this work.

\section{Ethical Approval}

This research has been approved by the Research Advisory Council (RAC) at the King Faisal Specialist Hospital and Research Centre, Riyadh, Saudi Arabia (RAC Project \# 2161 246).

\section{Data Availability statement}

All data are available with the corresponding author and can be provided upon request.

\section{Author contribution}

All authors contributed to the study conception and design. Material preparation, data collection and analysis were performed by [Ahmed Elashwah, Ali Alzahrani and Mohammad Breakeit). Surgical management and post operative follow up done by ( Tarek mahmoud Amin and Ayman Zaki Azzam). The radiation therapy indications and all IORT parameters chosen for every patient done by (Abdullah Alsuhaibani' Rana Mahmood and Ahmed Elashwah). The medical physics work done by (Belal Moftah, Muhammad Hussain, Shada ALramahi and Zeinab Hassan ). The first draft of the manuscript was written by [Ahmed Elashwah] and all authors commented on previous versions of the manuscript. All authors read and approved the final manuscript."

\section{References}

1. Leonard L. Gunderson, Christopher G. Willet, Louis B. Harrison,Felipe A. Calvo. Intraoperative irradiation: techniques and results. 2nd ed. New York: Human Press; 2011.2

2. M Abe, M Fukuda, K Yamano, S Matsuda, H Handa. Intraoperative radiation in abdominal and cerebral tumors, Acta Radio/ 10:408-416, 1971.

3. Gunderson LL, Willett C. In: Perez CA, Brady LW. Principles and practice of radiation oncology. 3rd ed. Philadelphia: J.B. Lippincott; 1997.

4. (4) Gunderson LL, Calvo FA, Willet CG. Rationale and historical perspective of intraoperative irradiation. In : Gunderson LL, Willet CG, Calvo FA, Harrison LB, editors. Intra operative irradiation: techniques and results. 2nd ed. NewYork: Human Press; 2011. p. 3-26.3.

5. Haddock MG, Martinez-Monge R, Petersen IA.Locally advanced primary and recurrent gynecologic malignancies. EBRT with or without IOERT or HDR-IORT. In: Gunderson LL, Calvo F, Harrison LB et al., eds. Current Clinical Oncology: Intraoperative Irradiation: Techniques and Results. New Totowa, NJ: Humana Press, 1999:397-419.

6. G R Garton, L L Gunderson, M J Webb, T O Wilson, J A Martenson Jr, S S Cha, K C Podratz. Intraoperative radiation therapy in gynecologic cancer: the Mayo Clinic experience. Gynecol Oncol 1993;48:328-332.

7. G R Garton ${ }^{1}$, L L Gunderson, M J Webb, T O Wilson, S S Cha, K C Podratz. Intraoperative radiation therapy in gynecologic cancer: update of the experience at a single institution. Int J Radiat Oncol Biol Phys 1997;37:839-843.

8. (8)AhmedAbu-Zaid, AymanAzzam, MohammedAbuzaid, Tusneem Elhassan, NarymanAlbadawi, LynnAlkhatib, OsamaAlOmar, Abdullah Alsuhaibani, TarekAmin, Ismail A Al-Badawi.Cytoreductive Surgery plus Hyperthermic Intraperitoneal Chemotherapy for Management of Peritoneal Sarcomatosis: A Preliminary Single-Center Experience from Saudi Arabia. Hindawi Publishing Corporation Gastroenterology Research and Practice Volume 2016, Article ID 6567473, 8 pages http://dx.doi.org/10.1155/2016/6567473.

9. Dindo D., Demartines N., Clavien P.-A. Classification of surgical complications: a new proposal with evaluation in a cohort of 6336 patients and results of a survey. Annals of Surgery. 2004;240(2):205-213. doi: 10.1097/01.sla.0000133083.54934.

10. Okunieff P, Sundararaman S, Chen Y: Biology of large dose per fraction radiation therapy. In Gunderson LL, Willett CG, Harrison LB, Calvo FA, editors: Intraoperative Irradiation-Techniques and Results, Totowa, NJ, 1999, Humana Press, pp 25-46.

11. C G Willett, P C Shellito, J E Tepper, R Eliseo, K Convery, W C Wood. Intra operative electron beam radiation therapy for primarily locally advanced rectal and recto sigmoid carcinoma. J Clin Onco/1991;9:843-9.5.. Electron beam radiation therapy for primarily locally advanced rectal and recto sigmoid carcinoma. J Clin Onco/1991;9:843-9.5. 
12. Felipe A Calvo, Marina Gómez-Espí, Juan A Díaz-González, Arnaldo Alvarado, Rocío Cantalapiedra, Pilar Marcos, Raúl Matute, Nuria E Martínez, Miguel A Lozano, Rafael Herranz. Intraoperative pre sacral electron boost following preoperative chemo radiation in T3-4Nx rectal cancer: initiallocal effects and clinical outcome analysis. Radiother Onco/2002;62:201-6.6.

13. Robert Krempien, Falk Roeder, Susanne Oertel, Marianne Roebel, Jürgen Weitz, Frank W Hensley, Carmen Timke, Angela Funk, Marc Bischof, Angelika Zabel-Du Bois, Andreas G Niethammer, Michael J Eble, Markus W Buchler, Martina Treiber, Jürgen Debus. Long term results of intra operative pre sacral electron boost radiotherapy(IOERT) in combination with total mesorectal excision (TME) and chemotherapy in patients with locally advanced rectal cancer. Int J Radiat Oncol Biol Phys2006;66:1143-51.7.

14. Kellie L Mathis, Heidi Nelson, John H Pemberton, Michael G Haddock, Leonard L Gunderson. Unresectable colorectal cancer can be cured with multimodality therapy Ann Surg 2008; 248:592-8.8.

15. Michael G Haddock, Robert C Miller, Heidi Nelson, John H Pemberton, Eric J Dozois, Steven R Alberts, Leonard L Gunderson. Combined modality therapy including intraoperative electron irradiation for locally recurrent colorectal cancer. Int J Radiat Oncol Bio/2011;79:14350.9 .

16. Reza Mirnezami, George J Chang, Prajnan Das, Kandiah Chandrakumaran, Paris Tekkis, Ara Darzi, Alexander H Mirnezami. Intraoperative radiotherapy in colorectal cancer: systematic review and meta-analysis of techniques, long-term outcomes, and complications. Surg Oncol 2013;22(1):22-35.11.

17. Jean-Bernard Dubois, Emmanuel Bussieres, Pierre Richaud, Philippe Rouanet, Yves Becouarn, Simone Mathoulin-Pélissier, Bernard SaintAubert, Marc Ychou. Intra-operative radiotherapy of rectal cancer: results of the French multi-institutional randomized study. Radio ther Oncol,2011;98:298-303.10. Intra-operative radiotherapy of rectal cancer: results of the French multi-institutional randomized study. Radio therapy Oncol2011;98:298-303.10.

18. Verwaal VJ ${ }^{1}$, van Ruth S, de Bree E, van Sloothen GW, van Tinteren H, Boot H, Zoetmulder FA Randomized trial of cytoreduction and hyperthermic intraperitoneal chemotherapy versus systemic chemotherapy and palliative surgery in patients with peritoneal carcinomatosis of colorectal cancerJ Clin Oncol. 2003 Oct 15;21(20):3737-43.

19. Gastrointestinal Tumor Study Group A comparison of combination chemotherapy and combined modality therapy for locally advanced gastric carcinoma. Cancer. 1982; 49:1771-1777.

20. J S Macdonald, S R Smalley, J Benedetti, S A Hundahl, N C Estes, G N Stemmermann, D G Haller, J A Ajani, L L Gunderson, J M Jessup, J A Martenson. Chemoradiotherapy after surgery compared with surgery alone for adenocarcinoma of the stomach or gastroesophageal junction. N Engl J Med. 2001; 345:725-730.

21. Yu WW, Guo YM, Zhang Q, Fu S. Benefits from adjuvant intraoperative radiotherapy treatment for gastric cancer: A meta-analysis. Mol Clin Oncol. 2015;3(1):185-189. doi:10.3892/mco.2014.444.

22. Peng Gao, Chengche Tsai, Yuchong Yang, Yingying Xu, Changwang Zhang, Cong Zhang, Longyi Wang, Hongpeng Liu, Zhenning Wang. Intraoperative radiotherapy in gastric and esophageal cancer: meta-analysis of long-term outcomes and complications. Minerva Med. 2017;108(1):74-83. doi:10.23736/S0026-4806.16.04628-0

23. Qin HL, Lin $\mathrm{CH}$, Zhang XL. Evaluation of intra operative radiotherapy for gastric carcinoma with D2 and D3surgical resection. World J Gastroentero/ 2006;12(43):7033-7.12.

24. Oliver Drognitz, Karl Henne, Christian Weissenberger, Gregor Bruggmoser, Heike Göbel, Ulrich Theodor Hopt, Herrmann Frommhold, Günther Ruf. Long-term results alter intraoperative radiation therapy for gastric cancer. Int J Radiat Oncol Biol Phys2008;72(3):715-21.13.

25. Fu S, Lu JJ, Zhang Q, Yang Z, Peng L, Xiong F. Intra operative radiotherapy combined with adjuvant chemo radiotherapy for locally advanced gastric adenocarcinoma. Int J RadiatOncol Biol Phys 2008;72(5):1488-94.14 55).

26. J D Spiliotis, E Halkia, V A Boumis, D T Vassiliadou, A Pagoulatou, E Efstathiou.Cytoreductive Surgery and HIPEC for Peritoneal Carcinomatosis in the Elderly. Int J Surg Oncol. 2014; 2014: 987475.

27. Naciye Cigdem Arslan, Tayfun Bisgin, Canan Altay, Tugba Yavuzsen, Aziz Karaoglu, Aras Emre Canda, Sulen Sarioglu, Selman Sokmen. Is advanced age a hesitation for cytoreductive surgery and hyperthermic intraperitoneal chemotherapy in colorectal cancer?. J BUON. 2018 Dec;23(7):77-83.

28. Wirginiusz Dziewirski, Piotr Rutkowski, Zbigniew I Nowecki, Maciej Sałamacha, Tadeusz Morysiński, Anna Kulik, Maria Kawczyńska, Anetta Kasprowicz, Jarosław Lyczek, Włodzimierz Ruka. Surgery combined with intraoperative brachytherapy in the treatment of retroperitoneal sarcomas. Ann Surg Oncol. 2006;13(2):245-52. doi: 10.1245/ASO.2006.03.026.

29. Raeshell S Sweeting, Allison M Deal, Omar H Llaguna, Brian K Bednarski, Michael O Meyers, Jen Jen Yeh, Benjamin F Calvo, Joel E Tepper, Hong Jin Kim. Intraoperative electron radiation therapy as an important treatment modality in retroperitoneal sarcoma. J Surg Res. 2013;185(1):245-9. doi: 10.1016/j.jss.2013.05.015.

30. Falk Roeder, Alexis Ulrich, Gregor Habl, Matthias Uhl, Ladan Saleh-Ebrahimi, Peter E Huber, Daniela Schulz-Ertner, Anna V Nikoghosyan, Ingo Alldinger, Robert Krempien, Gunhild Mechtersheimer, Frank W Hensley, Juergen Debus, Marc Bischof. Clinical phase I/II trial to investigate 
preoperative dose-escalated intensity-modulated radiation therapy (IMRT) and intraoperative radiation therapy (IORT) in patients with retroperitoneal soft tissue sarcoma: interim analysis. BMC Cancer.2014;14:617. doi: 10.1186/1471-2407-14-617.

31. Chee-Chee H Stucky ${ }^{1}$, Nabil Wasif, Jonathan B Ashman, Barbara A Pockaj, Leonard L Gunderson, Richard J Gray. Excellent local control with preoperative radiation therapy, surgical resection, and intra-operative electron radiation therapy for retroperitoneal sarcoma. J Surg Oncol. 2014;109(8):798-803. doi: 10.1002/jso.23576.

32. W F Sindelar, T J Kinsella, P W Chen, T F DeLaney, J E Tepper, S A Rosenberg, E Glatstein. Intraoperative radiotherapy in retroperitoneal sarcomas. Final results of a prospective, randomized, clinical trial. ArchSurg.

1993;128(4):40210doi10.1001/archsurg.1993.01420160040005.

33. Andreas du Bois, Alexander Reuss, Eric Pujade-Lauraine, Philipp Harter, Isabelle Ray-Coquard, Jacobus Pfisterer. Role of surgical outcome as prognostic factor in advanced epithelial ovarian cancer: a combined exploratory analysis of 3 prospectively randomized phase 3 multicenter trials: by the Arbeitsgemeinschaft Gynaekologische Onkologie Studiengruppe Ovarialkarzinom (AGO-OVAR) and the Groupe d'Investigateurs Nationaux Pour les Etudes des Cancers de l'Ovaire (GINECO). Cancer 2009; 115: 1234-1244.

34. M E van der Burg, M van Lent, M Buyse, A Kobierska, N Colombo, G Favalli, A J Lacave, M Nardi, J Renard, S Pecorelli. The effect of debulking surgery after induction chemotherapy on the prognosis in advanced epithelial ovarian cancer. Gynecological Cancer Cooperative Group of the European Organization for Research and Treatment of Cancer. N Engl J Med 1995; 332: 629-634.

35. (35). Vergote I, Tropé CG, Amant F, Kristensen GB, Ehlen T, Johnson N, Verheijen RH, van der Burg ME, Lacave AJ, Panici PB, Kenter GG, Casado A, Mendiola C, Coens C, Verleye L, Stuart GC, Pecorelli S, Reed NS. Neoadjuvant chemotherapy or primary surgery in stage IIIC or IV oavarian cancer. N Engl J Med 2010; 363: 943-953.

36. P Harter, M Hahmann, H J Lueck, M Poelcher, P Wimberger, O Ortmann, U Canzler, B Richter, U Wagner, A Hasenburg, A Burges, S Loibl, W Meier, J Huober, D Fink, W Schroeder, K Muenstedt, B Schmalfeldt, G Emons, A du Bois. Surgery for recurrent ovarian cancer: role of peritoneal carcinomatosis: exploratory analysis of the DESKTOP I Trial about risk factors, surgical implications, and prognostic value of peritoneal carcinomatosis. Ann Surg Oncol 2009; 16: 1324-1330.

37. R Y Zang, P Harter, D S Chi, J Sehouli, R Jiang, C G Tropé, A Ayhan, G Cormio, Y Xing, K M Wollschlaeger, E I Braicu, C A Rabbitt, H Oksefjell, W J Tian, C Fotopoulou, J Pfisterer, A du Bois, J S Berek. Predictors of survival in patients with recurrent ovarian cancer undergoing secondary cytoreductive surgery based on the pooled analysis of an international collaborative cohort. Br J Cancer 2011; 105: 890-896.

38. (38)Backes FJ, Martin DD. Intraoperative radiation therapy (IORT) for gynecologic malignancies. Gynecol Oncol. 2015;138(2):449-456. doi:10.1016/j.ygyno.2015.05.030

39. N Bakrin, E Cotte, F Golfier, F N Gilly, G Freyer, W Helm, O Glehen, J M Bereder. Cytoreductive surgery and hyperthermic intraperitoneal chemotherapy (HIPEC) for persistent and recurrent advanced ovarian carcinoma: a multicenter, prospective study of 246 patients. Ann Surg Oncol 2012; 19:4052.

40. Y Nishimura ${ }^{1}$, R Hosotani, Y Shibamoto, M Kokubo, S Kanamori, K Sasai, M Hiraoka, G Ohshio, M Imamura, M Takahashi, M Abe. External and intraoperative radiotherapy for resectable and unresectable pancreatic cancer: analysis of survival rates and complications. Int $J$ Radiat Oncol Biol Phys. 1997;39(1):39-49. doi:10.1016/s0360-3016(97)00295-2

41. Vincenzo Valentini ${ }^{1}$, Felipe Calvo, Michele Reni, Robert Krempien, Felix Sedlmayer, Markus W Buchler, Valerio Di Carlo, Giovanni B Doglietto, Gerd Fastner, José L Garcia-Sabrido, GianCarlo Mattiucci, Alessio G Morganti, Paolo Passoni, Falk Roeder, Giuseppe R D'Agostino. Intraoperative radiotherapy (IORT) in pancreatic cancer: joint analysis of the ISIORT-Europe experience. Radiother Oncol 2009;9:54-9. 17.

42. Keiichi Jingu ${ }^{1}$, Takaya Tanabe, Kenji Nemoto, Hisanori Ariga, Rei Umezawa, Yoshihiro Ogawa, Ken Takeda, Masashi Koto, Toshiyuki Sugawara, Masaki Kubozono, Eiji Shimizu, Keiko Abe, Shogo Yamada. Intraoperative radiotherapy for pancreatic cancer: 30-year experience in a single institution in Japan. Int J Radiat Oncol Biol Phys 2012;83(July 4:e507-11).

\section{Figures}


NO of IORT applications by year

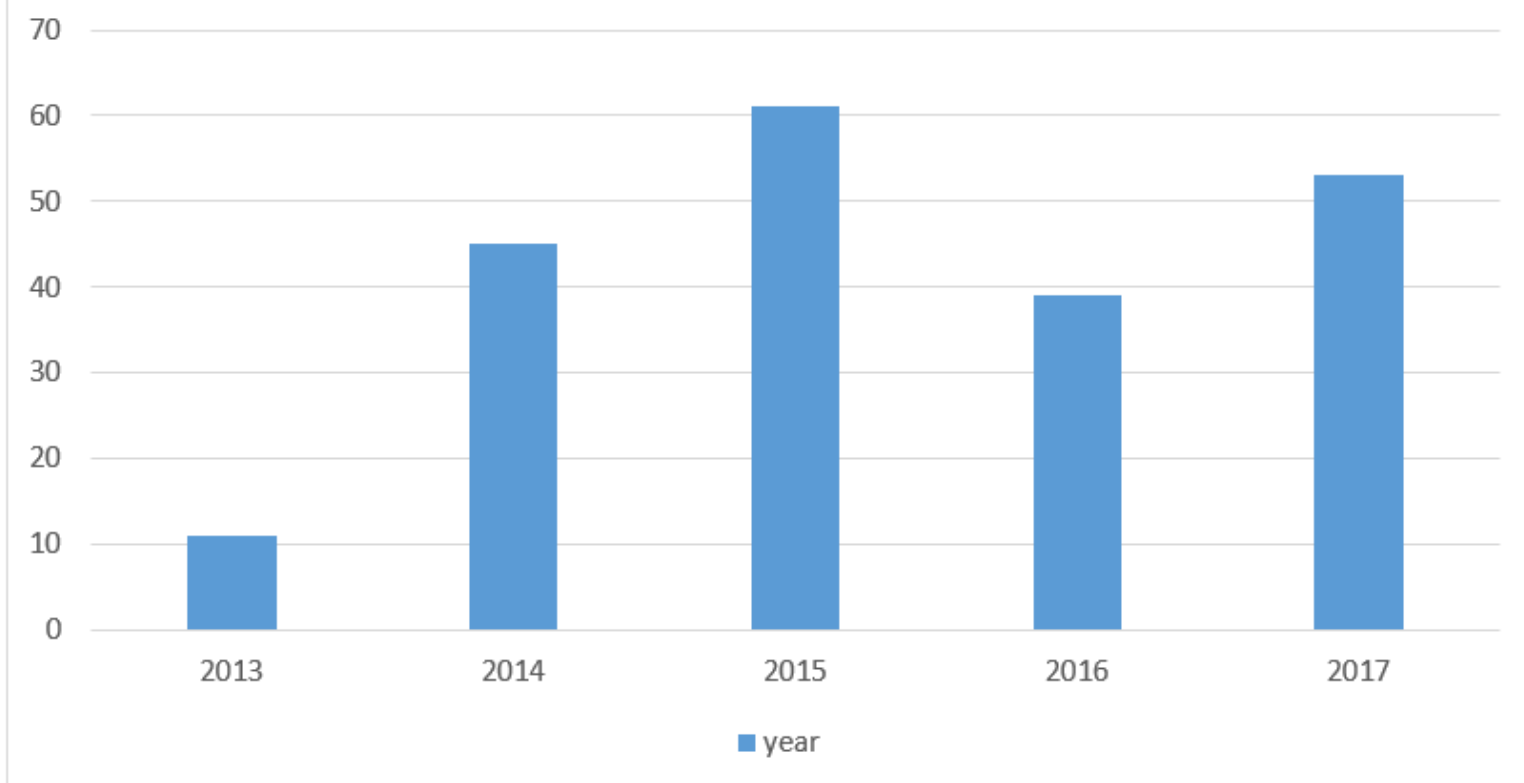

Figure 1

No of IORT applications by year

\section{Patients distribution by cancer site}

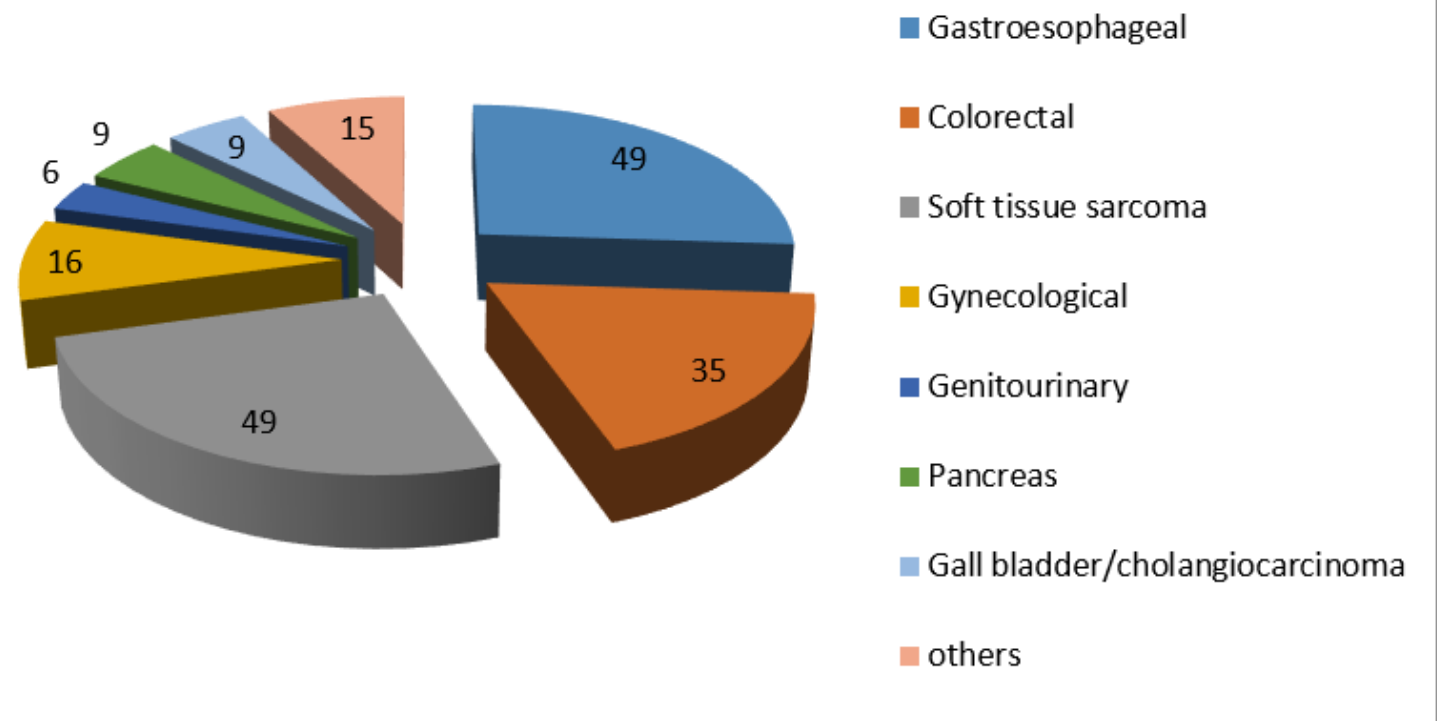

Figure 2

patients distribution by cancer site 


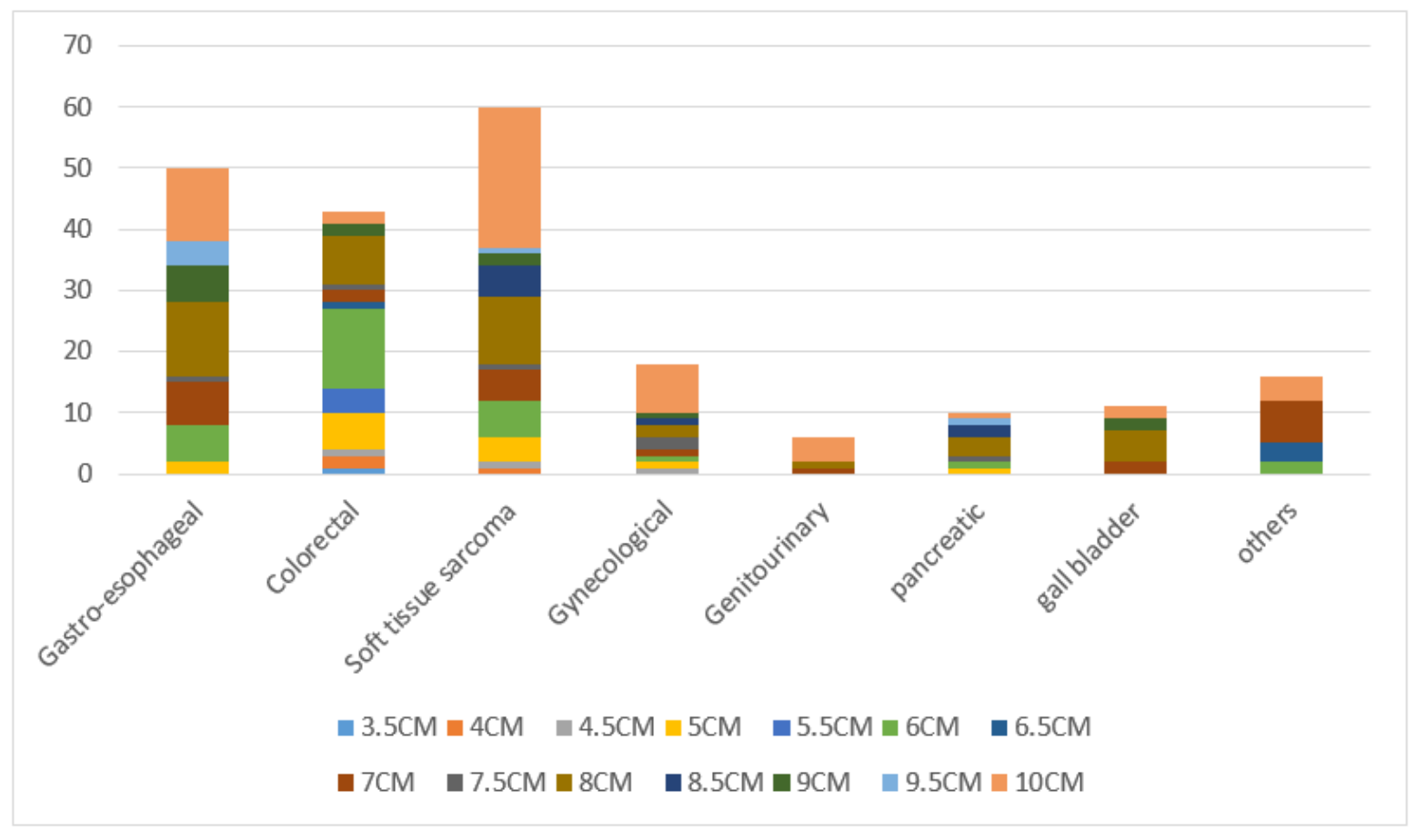

Figure 3

IORT applicator diameters used in different cancer sites

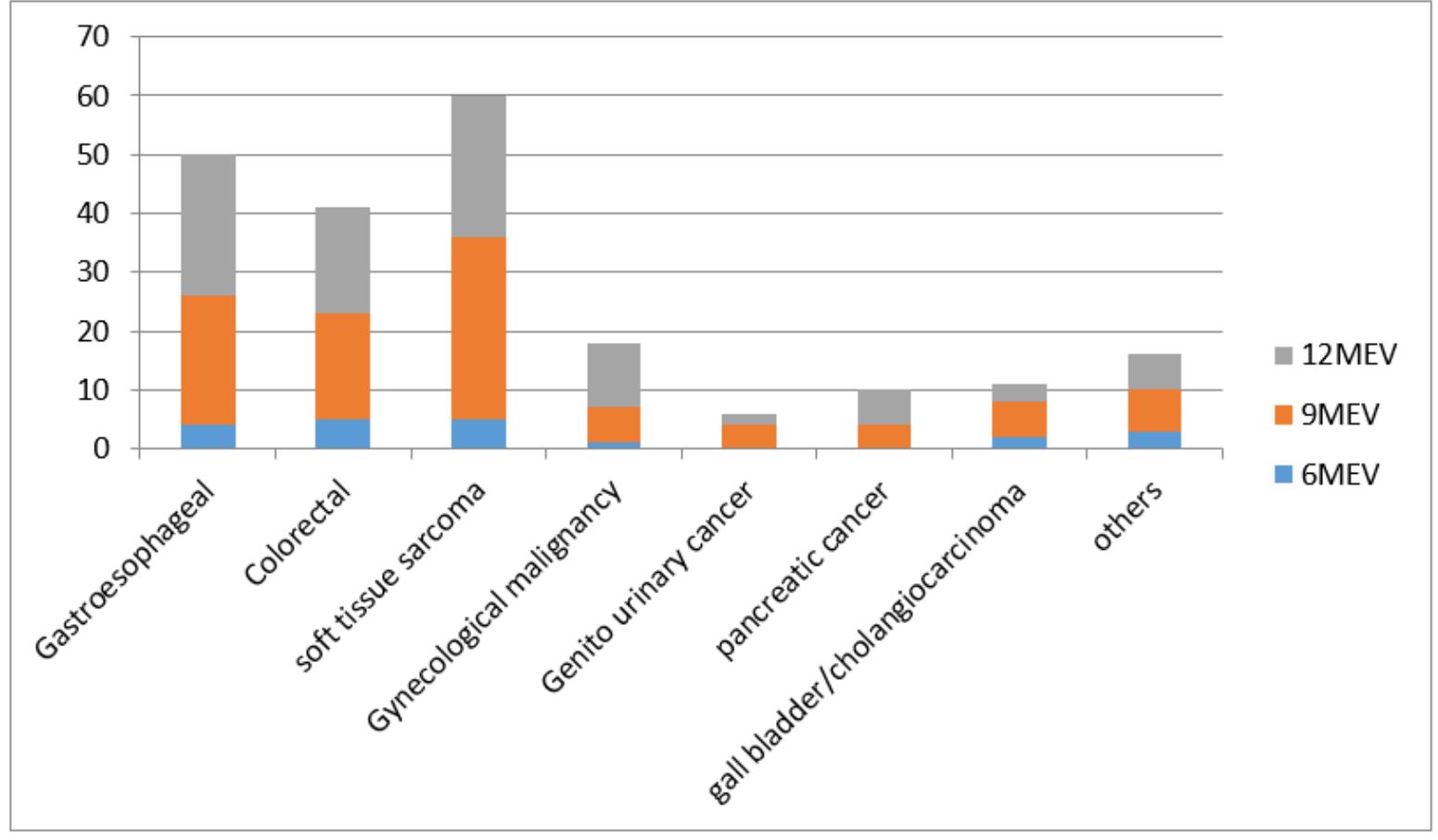

Figure 4

IORT electron beam energy used for each cancer sites. 


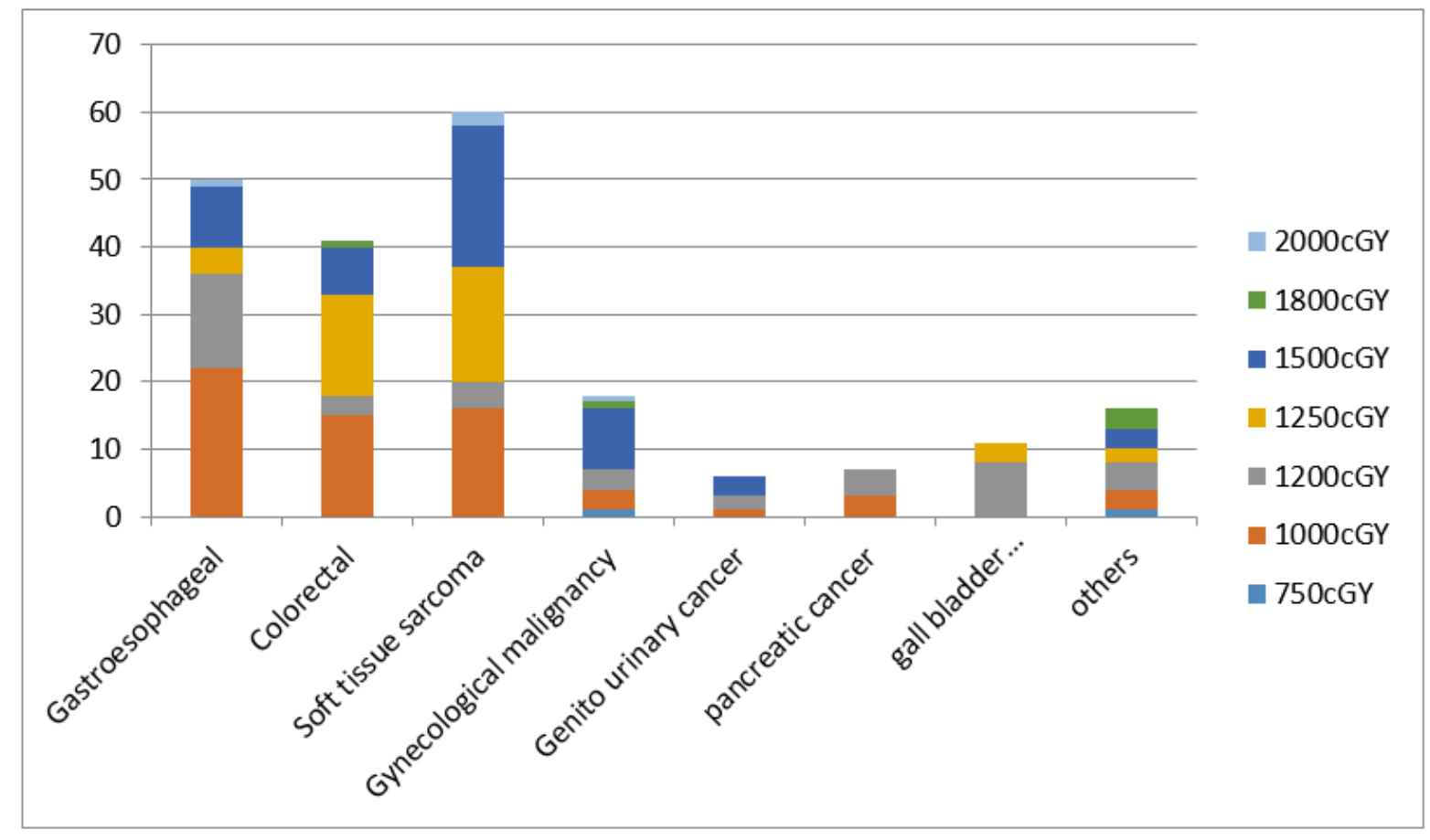

Figure 5

IORT dose delivered in each cancer site.

\section{Post operative complications according to the Clavien Dindo grading system}

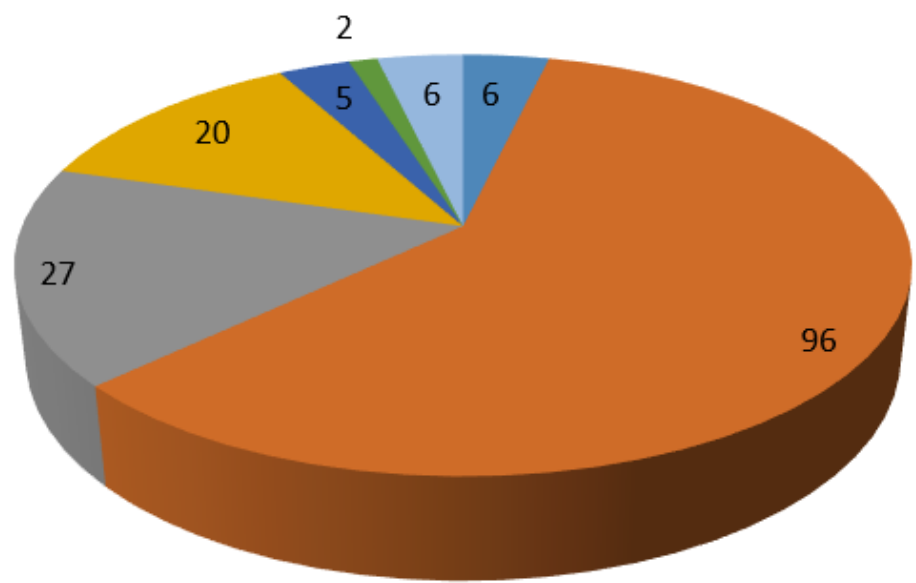

- Grade I

Grade II

Grade IIla

Grade IIIb

Grade IVa

Grade Ivb

Grade V

Figure 6

postoperative complications grades according to Clavien Dibdo grading system.

\section{Supplementary Files}

This is a list of supplementary files associated with this preprint. Click to download.

- IORTListDindo.xlsx 